\title{
Evaluation of selected Kenyan potato cultivars for processing into potato crisps
}

\author{
George O. Abong ${ }^{1^{*}}$, Michael W. Okoth ${ }^{1}$, Jasper K. Imungi ${ }^{1}$ and Jackson N. Kabira ${ }^{2}$ \\ ${ }^{1}$ Department of Food Science, Nutrition and Technology, University of Nairobi, P.O. Box \\ 29053-00625, Nairobi (Kangemi), Kenya; \\ ${ }^{2}$ National Potato Research Centre (KARI), Tigoni, P.O. Box 338, Limuru. Nairobi, Kenya. \\ *Corresponding author: Email: georkoyo@yahoo.com; Phone: 254735508558
}

\begin{abstract}
There has been tremendous increase in the demand and consumption of potato crisps as snack in Kenya. This has however, not been paralleled by development of appropriate raw materials. Many potato varieties and clones have been developed through breeding, but these have not been adequately evaluated for crisps processing. This study was therefore designed to evaluate the newly developed potato cultivars for processing into quality crisps. Twenty four potato cultivars including eighteen varieties and six clones were evaluated for some physico-chemical properties and crisps processing potential. Most cultivars with the exception of six of them including Roslin Tana, Desiree, Roslin Eburu, Nyayo, Tigoni Long and Kihoro had acceptable physical characteristics for processing. The specific gravity of the cultivars varied from 1.074 to 1.098 and dry matter contents from $19.50 \%$ to $24.20 \%$. Reducing sugar levels significantly ( $P \leq$ 0.05 ) varied among the cultivars and ranged between $0.07 \%$ and $0.4 \%$. In addition to Dutch Robyjn which is currently used for processing potato crisps in Kenya, the varieties Tigoni and Kenya Baraka, and the clones 393371.58, 392657.8, 391691.96 and 393385.39 were also similarly suitable for processing into potato crisps. They had desired physical characteristics with low levels of reducing sugars, and were highly rated by sensory panelists. Promoting these cultivars will increase the number of processing varieties for the rapidly expanding processing industry, and thus safeguard availability and quality.
\end{abstract}

Keywords: potato crisps, snacks, crisps colour, Dutch Robyjn

\section{INTRODUCTION}

Potatoes belong to the Solanaceae family commonly grown for starchy tubers. Potatoes are the World's most widely grown tuber crop and the fourth largest crop in terms of fresh produce after rice, wheat and maize (MoA, 2005). According to the National Policy on Potato Industry, the potato is an important food and cash crop that plays a major role in food security and is only second to maize in terms of utilization (MoA, 2007). Production is confined to the highlands (1500-3000 $\mathrm{m}$ above sea level), where the crop has highest yields. The growing areas of production include Central, Rift Valley, Eastern, and to a less extent the high levels of Western and Coast provinces. Potato production is increasing due to the economic decline of competing cash crops such as maize, pyrethrum and barley, and increasing demand from consumers and processors.

Over 60 potato varieties including Roslin Eburu, Roslin Tana, Roslin Gucha, Bvumbwe, Feldslohn,
Nyayo, Kenya Sifa, Kenya Baraka, Kenya Dhamana, Desiree, Asante, Tigoni, Annet, Arka, Kenya Mavuno, Dutch Robyjn and Kerr's Pink are currently grown and marketed in Kenya (MoA, 2007). In addition, the newer potato varieties developed by the National Potato Research Center (KARI-Tigoni) presumed to be superior to the existing ones in terms of disease tolerance (mainly late blight and viruses), require to be evaluated to establish their processing qualities. Among the existing varieties, the round red-skinned type Dutch Robyjn has been commonly used for crisps processing. The crisps processing characteristics of newer varieties Asante, Tigoni and Furaha have also been evaluated but this evaluation was limited to sensory testing (Kabira, 2000; Kabira, 2002). Many advanced potato clones from the International Potato Centre, Lima-Peru have been introduced into the national potato breeding programme. They are currently undergoing multilocational trials and at least six of them are undergoing national performance trials in 
collaboration with Kenya Plant Health Inspectorate Service (KEPHIS). Information on the processing characteristics of the new and promising cultivars is required in order to support the rapidly expanding potato industry with quality raw materials.

The most important products in the Kenyan potato processing industry are potato chips (fresh fries), crisps and frozen fries. The demand for all these products has greatly increased in the urban areas (Walingo et al., 2004; Kabira, 2007). The processing of potato crisps in Kenya has undergone tremendous growth over the last three decades. In early 1980s, only five processors existed in Nairobi city (Durr and Lorenzl, 1980). In a previous study by the present authors, at least 24 processors existed in the city. The potato varieties for processing into crisps vary among processors and countries depending on the suitability and availability. Crisps therefore, vary in quality depending on country of origin and the processor (Salvador et al., 2008).

The major hindrance to crisps processing in Kenya is the unavailability of sufficient quantities of appropriate quality potato cultivars (Kabira, 2007). Although potato crisps processing industry is an important outlet for Kenyan farmer's production, the country has only one variety for crisping. Unfortunately even for this variety, the best tubers for crisps come from only one region of the country, Bomet in the Rift Valley Province. Although the variety is the most favoured for processing, the tubers of Dutch Robyjn have medium to deep eyes which may lead to substantial peeling and trimming losses compared with varieties such as Tigoni having shallower eyes. Furthermore, a single variety cannot be relied on to supply sufficient raw material for an expanding local and exports crisps market. Several varieties and clones have been developed which can be evaluated to expand the available appropriate raw material (Walingo et al., 2007; Abong' et al., 2009). Indeed, during periods of scarcity the processors underutilize their installed capacity within factories with more than $50 \%$. During these periods also, the manufacturers use any available potato cultivars which lowers the general quality of crisps (Walingo et al., 2004).

Crisps quality is influenced by tuber size, shape, eye depth, specific gravity, dry matter and levels of reducing sugars. These factors depend on cultural practices, environmental conditions and genotype. The genetic component, however, has the strongest influence since the traits are heritable (Kabira and Lemaga, 2006; Abong' et al., 2009). This study was therefore designed to evaluate 24 potato cultivars including 18 varieties and 6 advanced potato clones for their suitability as raw materials for processing into potato crisps.

\section{MATERIALS AND METHODS}

Potato tuber production: Six promising clones coded as 392617.54, 393371.58, 385524.9, $392657.8,391691.96$ and 393385.39 from the International Potato Center (CIP) and eighteen varieties (Tigoni, Desiree, Dutch Robyjn, Kenya Karibu, Kenya Baraka, Cangi, Pimpernel, Roslin Tana, Asante, Kihoro, Kenya Furaha, Romano, Roslin Eburu, Arka, Kenya Mavuno, Tigoni Long, Nyayo and Kenya Sifa) were grown at the National Potato Research Center Tigoni (2100 m above sea level) in the year 2009/10 under standard cultural conditions (Lung'aho and Kabira, 1999). After maturity, the crop was dehaulmed two weeks before harvesting. Then, the tubers were harvested and allowed to cure in a common dark store under ambient air conditions $\left(17-22{ }^{\circ} \mathrm{C} / 84-92 \%\right.$ rh) for two weeks at the National Potato Research Center in Tigoni. They were then analyzed for physical characteristics at Tigoni and for crisping property at a processing company. The dry matter content and reducing sugars levels were analyzed at the Department of Food Science, Nutrition and Technology, University of Nairobi.

Physical tuber characteristics: The physical tuber characteristics (shape, size, skin and flesh colour, and eye depth), were determined according to the methods described by Kabira and Lemaga (2006) and Abong' (2009).

Tuber shape, size and eye depth: For 10 representative tubers shapes were determined by observation the shape was designated as round, elongated, oblong, long oval, pointed oval or oval. The samples were measured for size and eye depths using a vernier caliper (NSK Nippon Sokutei, Japan) and a ruler (Aim, Kenya), respectively. Size was determined in terms of diameter. Eye depth was recorded as shallow $(0.00-0.20 \mathrm{~mm})$, medium $(0.20$ $0.50 \mathrm{~mm}$ ) or deep $(>0.60 \mathrm{~mm})$. Round tubers with shallow or medium eye depths and of size $40-60 \mathrm{~mm}$ in diameter were considered suitable for processing.

Skin and flesh colour: Five representative tubers were picked at random from a net bag of $10 \mathrm{~kg}$ of each cultivar and visually examined for skin colour which was recorded as cream, red, white, pink or purple. Each tuber was then cut with a knife 
longitudinally and flesh colours recorded as white, yellow or cream.

Specific gravity and dry matter content: Specific gravity was determined in the raw tubers according to weight under water method as described by Ludwig (1972). Tubers with specific gravity of $\geq 1.080$ were considered suitable for crisps processing. For determination of dry matter, five whole tubers were randomly selected from each cultivar and cut into small slices (1-2 $\mathrm{mm})$ and mixed thoroughly. Dry matter contents were then determined by drying triplicate $20 \mathrm{~g}$ samples at $80{ }^{\circ} \mathrm{C}$ for $72 \mathrm{hr}$ in a forced air oven. Tubers with dry matter contents $\geq 20 \%$ were considered ideal for crisps processing.

Reducing sugars: Reducing sugars were determined on triplicate samples by the Luff-Schoorl method number 4 of the International Federation of Fruit Juice Producers (1985). Tubers with reducing sugars contents of $\leq 0.25 \%$ were considered ideal for crisps processing.

Potato crisps preparation and evaluation: Potato tubers were peeled, and sliced using an automatic electric slicer (Hitech Systems, Saudi Arabia) to a uniform thickness of $1.5 \mathrm{~mm}$. These slices were washed in cold tap water to remove surface starch dewatered by centrifuging (PPM No. 824, Sweden) at $3000 \mathrm{rpm}$ for 3-5 min. The potato slices were then fried in an institution size, batch type, and deep oil fryer (E 6 ARO S.A., La Neuveville, Switzerland) containing about 10 litres of "Cheff" corn oil maintained at a fixed temperature of $170{ }^{\circ} \mathrm{C}$ for $3-5$ min. The fried slices were removed and excess oil drained off for $1 \mathrm{~min}$, placed on plates, cooled and taken for evaluation.

Crisp colour was determined according to PC/SFA (1987) colour chart ranging from a score of 1 to a score of 5 . A score of 2.5 was the maximum acceptability score.

For sensory evaluation, coded samples were presented to 10 panelists, all familiar with potato crisps. Panel members scored for colour, texture, flavour, oiliness and overall acceptability on a 7-point hedonic rating scale with $1=$ dislike very much to $7=$ like very much. A score of 4 was the lower limit of acceptability (Larmond, 1977).

Data analysis: Data were subjected to analysis of variance (ANOVA) and means separated by least significant difference test using Statistical Analysis System (SAS version 9). Pearson correlation analysis was also performed to determine linear relationships where necessary.

\section{RESULTS AND DISCUSSION}

Physical tuber characteristics: The physical tuber characteristics of tuber shape, size, skin and flesh colour, and eye depth are shown in Table 1. Majority cultivars, with exception of Roslin Tana, Desiree, Roslin Eburu, Nyayo and Tigoni Long which had long or pointed oval shapes, were round in shape. Tuber shape is an important characteristic in influencing peeling and trimming efficiency during processing. Potato tubers that are round in shape have been shown to be suitable for crisps processing for most processors because they easily make the required crisp diameters (Kulkarni and Govinden, 1994; Kabira and Lemaga, 2006). On the basis of shape alone all the cultivars with round shape had potential to be processed to crisps that conformed to specifications. The long and oval tubers, however, lend themselves easily for processing of French fries (Kabira and Lemaga, 2006; Abong' et al., 2009).

With the exception of variety Kihoro that had deep eyes, all cultivars had tubers with either shallow or medium eye depths. Deep eye depths lead to heavy losses during peeling and trimming and overall lowered yields of crisps (Smith, 1975; Kabira and Lemaga, 2006). Most cultivars had white, cream or red skin colours with the exception of clone 391691.96 that had dark-purple skin. White or red skin colours are associated with good quality by many Kenyan consumers (Kabira, 2000). The clone 391691.96 is an exception; dark purple skin colour is a rare appearance and may not be popular with the consumers at the initial stages of introduction but may trigger curiosity.

Tuber size, specific gravity, dry matter, reducing sugars content: Tuber diameter varied significantly $(P \leq 0.05)$ among the cultivars ranging from $43 \mathrm{~mm}$ in Tigoni Long to $56 \mathrm{~mm}$ in Kenya Sifa and clone 392617.54 (Table 2). All the cultivars therefore had tuber sizes within recommended range for crisps (40$60 \mathrm{~mm}$ in diameter). Tuber size directly influences crisp size, which in turn influences post-frying handling. Larger tubers than $60 \mathrm{~mm}$ in diameter yield crisps which are fragile and break easily during packaging and transport (Kabira and Lemaga, 2006). Specific gravity and dry matter contents differed significantly $(P \leq 0.05)$ among the cultivars. The specific gravity of cultivars varied from 1.074 in Kenya Furaha and Tigoni Long to 1.098 in Roslin Eburu. All the cultivars except Tigoni Long, Kenya Furaha, Romano and clone 392617.54 had specific 
gravity greater than 1.080 that is recommended for crisps processing.

Dry matter content ranged from $19.50 \%$ in Kenya Furaha and Tigoni Long to $24.20 \%$ in Roslin Eburu. Potato tuber specific gravity and dry matter content are very important characteristics in determining suitability of cultivars for crisps. Tubers with high specific gravity and dry matter generally give higher yields of crisps, have lower oil absorption and better texture and therefore are more economical to process (Lulai and Orr, 1979; Burton, 1989). Potato crisps processing requires tubers with dry matter content of greater or equal to $20 \%$ and specific gravity of greater or equal to 1.080 (Kabira and Lemaga, 2006). Therefore, based on specific gravity and dry matter content selection criteria, all cultivars except Tigoni Long, Kenya Furaha, Romano and clone 392617.54 were suitable for processing.
Reducing sugars levels significantly $(P \leq 0.05)$ varied among the cultivars ranging from $0.07 \%$ in clone 392617.54 to $0.4 \%$ in variety Romano. Besides factors such as environmental (such as temperature) or cultural practices (such as mineral nutrition, harvesting and storage conditions), genetic disposition has a strong influence on reducing sugar accumulation (Kumar et al., 2004). Reducing sugars react with amino acids in non-enzymic browning during frying of crisps to give them a golden brown colour. The levels of of reducing sugars and amino acids present in the potato therefore determine the extent of the brown colour formation. Very high levels of reducing sugars would result in undesirable dark brown crisps as opposed to the required golden brown color (Hamernik and Hanneman, 1998; Guar et al., 1999; Olsson et al., 2004; Abong' et al., 2009).

Table 1: Physical tuber quality characteristics of twenty four potato cultivars

\begin{tabular}{|c|c|c|c|c|}
\hline Cultivar & Shape & Skin colour & Flesh colour & Eye depth \\
\hline Tigoni & Round & Cream & Cream & Shallow \\
\hline Dutch Robyjn & Round & Red & Cream-yellow & Medium \\
\hline Kenya Karibu & Round & Deep-Red & Yellow & Medium \\
\hline Kenya Sifa & Flat/round & Red-pink & Cream & Shallow/Medium \\
\hline Asante & Round & Red & White & Medium \\
\hline 392617.54 & Round & White & White & Medium \\
\hline 393385.39 & Round & Red & White & Medium \\
\hline 393371.58 & Round & Cream & White & Shallow \\
\hline 385524.9 & Round & Cream & White & Shallow \\
\hline 392657.8 & Round & Cream & White & Shallow \\
\hline 391691.96 & Round & Dark-purple & Cream & Shallow \\
\hline Kihoro & Round & Cream/yellow & Cream & Deep \\
\hline Kenya Furaha & Round & Yellow & Cream & Shallow \\
\hline Romano & Round & Red & White & Shallow \\
\hline Roslin Tana & Long oval & White/yellow & Yellow & Shallow \\
\hline Roslin Eburu & Pointed oval & White/yellow & White & Shallow \\
\hline Arka & Round-oval & Red & Cream & Shallow \\
\hline Pimpernel & Round & Red & Cream & Shallow \\
\hline Kenya Baraka & Round & Cream & White & Shallow \\
\hline Kenya Mavuno & Round & Cream/yellow & Cream-yellow & Shallow \\
\hline Nyayo & Pointed oval & Cream white & Cream-yellow & Shallow \\
\hline Tigoni long & Long oval & Cream/white & Cream-yellow & Shallow \\
\hline Desiree & Long oval & Red & Cream-yellow & Shallow \\
\hline Cangi & Round & Cream & Cream-yellow & Medium \\
\hline
\end{tabular}


Table 2: Tuber diameter, specific gravity, dry matter and reducing sugars content

\begin{tabular}{|c|c|c|c|c|}
\hline Cultivar & Diameter (mm) & Specific gravity & $\begin{array}{l}\text { Dry matter content } \\
(\%)\end{array}$ & $\begin{array}{l}\text { Reducing sugars } \\
(\%)\end{array}$ \\
\hline 392617.54 & $56.00 \pm 1.41$ & $1.079 \pm 0.000$ & $20.22 \pm 0.06$ & $0.07 \pm 0.04$ \\
\hline 385524.9 & $45.50 \pm 0.71$ & $1.080 \pm 0.001$ & $20.75 \pm 0.16$ & $0.38 \pm 0.18$ \\
\hline 392657.8 & $55.50 \pm 0.71$ & $1.082 \pm 0.001$ & $21.00 \pm 0.13$ & $0.23+0.04$ \\
\hline 393371.58 & $53.50 \pm 0.70$ & $1.093 \pm 0.001$ & $23.19 \pm 0.10$ & $0.18 \pm 0.11$ \\
\hline 393385.39 & $48.00 \pm 2.28$ & $1.087 \pm 0.000$ & $22.06 \pm 0.07$ & $0.25 \pm 0.00$ \\
\hline 391691.96 & $50.00 \pm 0.00$ & $1.080 \pm 0.001$ & $20.82 \pm 0.26$ & $0.18 \pm 0.11$ \\
\hline Arka & $45.50 \pm 0.71$ & $1.084 \pm 0.003$ & $21.60 \pm 0.58$ & $0.18 \pm 0.12$ \\
\hline Asante & $47.50 \pm 3.53$ & $1.082 \pm 0.000$ & $21.07 \pm 0.03$ & $0.10 \pm 0.00$ \\
\hline Roslin Eburu & $48.00 \pm 2.83$ & $1.098 \pm 0.000$ & $24.20 \pm 0.13$ & $0.28 \pm 0.16$ \\
\hline Kenya Baraka & $45.50 \pm 0.71$ & $1.092 \pm 0.001$ & $23.10 \pm 0.16$ & $0.10 \pm 0.07$ \\
\hline Desiree & $54.00 \pm 1.41$ & $1.080 \pm 0.000$ & $20.70 \pm 0.03$ & $0.20 \pm 0.07$ \\
\hline Dutch Robyjn & $45.50 \pm 0.71$ & $1.093 \pm 0.001$ & $23.26 \pm 0.33$ & $0.10 \pm 0.00$ \\
\hline Kenya Furaha & $46.50 \pm 0.71$ & $1.074 \pm 0.000$ & $19.50 \pm 0.19$ & $0.28 \pm 0.04$ \\
\hline Kenya Karibu & $52.00 \pm 0.00$ & $1.080 \pm 0.000$ & $20.70 \pm 0.03$ & $0.08 \pm 0.04$ \\
\hline Kihoro & $50.50 \pm 0.71$ & $1.085 \pm 0.000$ & $21.57 \pm 0.16$ & $0.05 \pm 0.07$ \\
\hline Kenya Mavuno & $46.00 \pm 0.00$ & $1.087 \pm 0.000$ & $22.13 \pm 0.03$ & $0.18 \pm 0.11$ \\
\hline Nyayo & $52.00 \pm 0.00$ & $1.097 \pm 0.001$ & $24.13 \pm 0.23$ & $0.35 \pm 0.00$ \\
\hline Pimpernel & $50.00 \pm 0.00$ & $1.094 \pm 0.000$ & $23.52 \pm 0.03$ & $0.26 \pm 0.00$ \\
\hline Romano & $51.00 \pm 1.41$ & $1.075 \pm 0.001$ & $19.64 \pm 0.06$ & $0.40 \pm 0.14$ \\
\hline Cangi & $46.00 \pm 0.00$ & $1.080 \pm 0.000$ & $20.74 \pm 0.00$ & $0.38 \pm 0.17$ \\
\hline Kenya Sifa & $56.00 \pm 0.00$ & $1.080 \pm 0.000$ & $20.70 \pm 0.03$ & $0.18 \pm 0.11$ \\
\hline Roslin Tana & $50.25 \pm 0.35$ & $1.085 \pm 0.000$ & $21.80 \pm 0.23$ & $0.23 \pm 0.04$ \\
\hline Tigoni Long & $43.00 \pm 0.00$ & $1.074 \pm 0.008$ & $19.50 \pm 0.51$ & $0.10 \pm 0.00$ \\
\hline Tigoni & $46.00 \pm 0.00$ & $1.088 \pm 0.000$ & $22.22 \pm 0.16$ & $0.05 \pm 0.07$ \\
\hline
\end{tabular}

Results are means of three determinations \pm standard deviation

Table 3: Pearson correlation coefficient ( $r$ ) between PCISFA colour scores for crisps and levels of reducing sugars in raw potatoes

\begin{tabular}{|l|c|c|}
\hline Parameters & $\begin{array}{l}\text { PC/SFA colour } \\
\text { score }\end{array}$ & $\begin{array}{l}\text { Reducing } \\
\text { sugars }\end{array}$ \\
\hline $\begin{array}{l}\text { PC/SFA colour } \\
\text { score }\end{array}$ & 1.00 & $-0.53^{\mathrm{a}}$ \\
\hline Reducing sugars & $-0.53^{\mathrm{a}}$ & 1.00 \\
\hline
\end{tabular}

${ }^{\mathrm{a}}$ Significant correlation coefficient $(\mathrm{P}=0.0078) .(\mathrm{N}=24)$

There was a significant $(P \leq 0.05)$ correlation $(r=-0.53)$ between reducing sugar contents and PC/SFA color scores that confirms the influence of reducing sugars on crisps colour (Table 3). Based on reducing sugar content, all the cultivars tested in this study except clone 385524.9 and varieties Roslin Eburu, Kenya Furaha, Nyayo, Pimpernel, Romano and Cangi could be used for crisping.

Sensory quality characteristics: Table 4 shows average sensory and PC/SFA colour scores for crisps processed from 18 potato varieties and 6 clones. The sensory attributes of potato crisps that were evaluated differed significantly $(P \leq 0.05)$ among the cultivars. Variety Roslin Eburu had the highest colour score (5.68) while Cangi had the lowest score (2.73). Colour is one of the most critical sensory properties that determines acceptability of a food (Surkan et al., 2009) and hence must conform to consumer requirement (Krokida et al., 2001). Since 
there was a high correlation $(r=-0.92)$ between PC/SFA and sensory colour scores for potato crisps processed from the 24 cultivars, it therefore means that the panelists scores were in agreement with the objective colour measurement (Table 5). Varieties Table 4: Mean sensory and PC/SFA colour scores crisps processed from 18 potato varieties and 6 advanced clones $^{3}$

\begin{tabular}{|c|c|c|c|c|c|c|}
\hline Cultivar & Colour $^{1}$ & Flavour $^{1}$ & Texture $^{1}$ & Oiliness $^{1}$ & $\begin{array}{l}\text { Overall } \\
\text { acceptability }^{1}\end{array}$ & $\begin{array}{l}\text { PCISFA } \\
\text { colour score }^{2}\end{array}$ \\
\hline Dutch Robyjn & $4.86 \pm 1.13$ & $4.95 \pm 1.13$ & $5.18 \pm 1.33$ & $4.81 \pm 1.26$ & $5.32 \pm 1.36$ & $1.30 \pm 0.17$ \\
\hline Kenya Baraka & $4.82 \pm 1.05$ & $4.95 \pm 1.21$ & $5.05 \pm 0.84$ & $5.05 \pm 0.90$ & $4.95 \pm 0.95$ & $1.38 \pm 0.18$ \\
\hline Kenya Mavuno & $3.45 \pm 1.06$ & $4.09 \pm 1.48$ & $4.05 \pm 1.39$ & $3.91 \pm 1.58$ & $3.95 \pm 1.36$ & $2.63 \pm 0.18$ \\
\hline Asante & $3.41 \pm 1.18$ & $4.14 \pm 1.08$ & $4.50 \pm 1.37$ & $4.32 \pm 1.09$ & $4.08 \pm 1.09$ & $2.65 \pm 0.18$ \\
\hline Kenya Furaha & $3.73 \pm 1.42$ & $3.95 \pm 1.46$ & $4.09 \pm 1.44$ & $4.05 \pm 1.62$ & $4.09 \pm 1.23$ & $2.55 \pm 0.35$ \\
\hline Nyayo & $4.14 \pm 1.28$ & $4.45 \pm 1.30$ & $4.77 \pm 0.97$ & $4.82 \pm 1.05$ & $4.86 \pm 1.12$ & $2.48 \pm 0.18$ \\
\hline Tigoni & $4.60 \pm 1.17$ & $4.77 \pm 1.30$ & $4.50 \pm 1.37$ & $4.73 \pm 1.49$ & $5.00 \pm 1.29$ & $1.75 \pm 0.35$ \\
\hline Arka & $3.59 \pm 1.67$ & $4.18 \pm 1.50$ & $4.45 \pm 1.56$ & $4.32 \pm 1.25$ & $4.09 \pm 1.54$ & $2.53 \pm 0.18$ \\
\hline Romano & $3.45 \pm 1.01$ & $4.00 \pm 1.31$ & $4.23 \pm 1.19$ & $4.14 \pm 1.39$ & $4.14 \pm 1.28$ & $2.63 \pm 0.18$ \\
\hline Roslin Eburu & $5.68 \pm 0.84$ & $5.41 \pm 0.85$ & $5.41 \pm 0.91$ & $5.14 \pm 0.89$ & $5.50 \pm 1.10$ & $1.45 \pm 0.35$ \\
\hline Pimpernel & $4.64 \pm 1.05$ & $4.86 \pm 1.16$ & $4.95 \pm 0.95$ & $4.73 \pm 1.08$ & $5.00 \pm 1.11$ & $2.15 \pm 0.18$ \\
\hline Kihoro & $3.18 \pm 1.36$ & $3.50 \pm 1.44$ & $3.82 \pm 1.44$ & $4.36 \pm 1.17$ & $4.09 \pm 1.23$ & $2.93 \pm 0.18$ \\
\hline Desiree & $4.20 \pm 1.39$ & $4.32 \pm 1.27$ & $4.52 \pm 1.13$ & $4.55 \pm 1.04$ & $4.61 \pm 1.18$ & $2.13 \pm 0.53$ \\
\hline Roslin Tana & $4.50 \pm 1.12$ & $4.33 \pm 1.32$ & $4.20 \pm 1.13$ & $4.40 \pm 1.22$ & $4.43 \pm 1.34$ & $2.00 \pm 0.00$ \\
\hline Cangi & $2.73 \pm 1.70$ & $3.41 \pm 1.82$ & $3.32 \pm 1.76$ & $3.64 \pm 1.59$ & $3.64 \pm 1.50$ & $3.25 \pm 0.35$ \\
\hline 392657.8 & $5.27 \pm 0.83$ & $5.18 \pm 1.44$ & $5.27 \pm 1.39$ & $5.00 \pm 1.35$ & $4.90 \pm 1.25$ & $1.75 \pm 0.35$ \\
\hline 391691.96 & $5.00 \pm 1.19$ & $4.27 \pm 1.28$ & $4.59 \pm 1.10$ & $5.00 \pm 1.07$ & $5.30 \pm 0.97$ & $1.25 \pm 0.35$ \\
\hline 385524.9 & $4.27 \pm 1.49$ & $4.32 \pm 1.24$ & $4.73 \pm 1.24$ & $4.68 \pm 0.89$ & $4.86 \pm 1.04$ & $2.23 \pm 0.18$ \\
\hline 393371.58 & $4.64 \pm 1.50$ & $4.64 \pm 1.43$ & $4.64 \pm 1.59$ & $4.59 \pm 1.37$ & $4.68 \pm 1.52$ & $2.25 \pm 0.00$ \\
\hline 392617.54 & $5.45 \pm 0.91$ & $5.50 \pm 1.01$ & $5.32 \pm 1.17$ & $5.14 \pm 1.13$ & $5.45 \pm 1.26$ & $1.25 \pm 0.35$ \\
\hline Tigoni Long & $4.02 \pm 1.60$ & $4.32 \pm 1.35$ & $4.68 \pm 1.25$ & $4.45 \pm 1.33$ & $4.55 \pm 1.19$ & $2.35 \pm 0.35$ \\
\hline Kenya Sifa & $4.23 \pm 1.41$ & $4.64 \pm 1.43$ & $4.50 \pm 1.54$ & $4.59 \pm 1.33$ & $4.77 \pm 1.19$ & $2.25 \pm 0.17$ \\
\hline 393385.39 & $4.36 \pm 1.33$ & $4.95 \pm 1.53$ & $5.05 \pm 1.33$ & $5.14 \pm 1.08$ & $5.32 \pm 1.17$ & $2.33 \pm 0.35$ \\
\hline Kenya Karibu & $4.36 \pm 1.56$ & $4.45 \pm 1.59$ & $4.41 \pm 1.33$ & $4.59 \pm 1.86$ & $4.32 \pm 1.86$ & $2.28 \pm 0.18$ \\
\hline
\end{tabular}

Evaluation was done on 7-point hedonic scale. A score of 4 was the acceptable lower limit.

${ }^{2}$ Scores of 2.5 and below were acceptable on a scale of 1 to 5 .

${ }^{3}$ All figures are mean \pm standard deviation

Flavour scores ranged from 3.4 in Cangi to 5.4 in Roslin Eburu. The flavor perception significantly $(P \leq 0.05)$ varied among the cultivars. The low scores exhibited by Cangi may have resulted from the dark brown colour and the burnt flavor. Flavor is influenced by genetic component of the potato
Kenya Mavuno, Asante, Kenya Furaha, Arka, Romano and Kihoro had colour scores below the acceptable limit of 4.0 . 
Agric. Biol. J. N. Am., 2010, 1(5): 886-893

varied definitions that can be sorted in two main groups: those that give more importance to the noise produced when the crisp is chewed and another group that emphasizes the force applied to the material and its mechanical properties (Rojo and Vincent, 2008). Depending on the tuber characteristics especially dry matter and processing conditions, the texture can be too hard or too soft (soggy). It is, however, noted that all the cultivars evaluated except Cangi had scores above the limit of acceptability. On oiliness, variety Cangi scored the lowest (3.64) compared to Kenya Sifa and clone 392617.54 which scored the highest (5.14). Oiliness in crisps is as a result of the total oil absorbed or that which adheres to the surface. It depends on tuber characteristics and processing conditions. In the current study, all the cultivars except varieties Kenya Mavuno and Cangi had acceptable scores on oiliness. On overall acceptability, all the varieties and clones were generally acceptable with the exception of varieties Cangi and Kenya Mavuno that had scores of 3.64 and 3.95 , respectively.

Table 5: Pearson correlation coefficient ( $r$ ) between PCISFA and sensory colour scores for crisps made from 24 cultivars

\begin{tabular}{|l|c|c|}
\hline Parameters & $\begin{array}{l}\text { PC/SFA colour } \\
\text { score }\end{array}$ & $\begin{array}{l}\text { Sensory colour } \\
\text { score }\end{array}$ \\
\hline $\begin{array}{l}\text { PC/SFA colour } \\
\text { score }\end{array}$ & 1.00 & $-.92^{\mathrm{a}}$ \\
\hline $\begin{array}{l}\text { Sensory colour } \\
\text { score }\end{array}$ & $-0.92^{\mathrm{a}}$ & 1.00 \\
\hline
\end{tabular}

${ }^{\mathrm{a}}$ Significant correlation coefficient $(\mathrm{P}=0.000) .(\mathrm{N}=24)$

\section{CONCLUSION AND RECOMMENDATIONS}

Having considered the most critical characteristics including shape, eye depth, size, specific gravity, dry matter and reducing sugars of the potato tubers and sensory properties of crisps prepared from the 24 cultivars, varieties Dutch Robyjn, Tigoni and Kenya Baraka and clones 393371.58, 392657.8, 391691.96 and 393385.39 were suitable for processing into potato crisps. Tubers of Dutch Robyjn, Tigoni, 391691.96 and 393385.39 were, however, most suitable and could be promoted for commercial use by the potato industry. Variety Tigoni that is known to be high yielding can produce equally good quality crisps and should be promoted alongside Dutch Robyjn that is the variety available currently to many crisps processors in Kenya. The advanced clones 391691.96 and 393385.39 performed farely well compared to Dutch Robyjn. The National Potato Research Centre (KARI) should therefore ensure adequate production and distribution of these cultivars to farmers for supply to processors.

\section{ACKNOWLEDGEMENTS:}

Authors are grateful to the University of Nairobi, DAAD Nairobi office and the National Potato Research Centre (KARI) for financial support. We recognize the role played by potato breeders; Dr. J. Landeo (CIP), Mr. S. Nderitu, Mr. J. Karinga and Mr. J. Onditi (NPRC) who ensured that the materials were available. We appreciate the Food Science Department team at KARI-Tigoni led by Mrs. N. Ngone and Mr. K. Bethuel who offered their service during sample preparation and evaluation. Laboratory analysis was accomplished with assistance from Mr. J. M'Thika and Ms. R. Kamau, Food Science Laboratory Technicians at the University of Nairobi. The authors also recognize the support from Deepa Industries Ltd and especially the Quality Assurance manager, Ms. M. Wanjiru.

\section{REFERENCES}

Abong', G.O., Okoth, M.W., Karuri, E.G., Kabira, J.N and Mathooko, F.M. (2009). Levels of reducing sugars in eight Kenyan potato cultivars as influenced by stage of maturity and storage conditions. J. Anim. and Plant Sci. 2 (2): $76-84$.

Burton, W.G. (1989). The potato. $3^{\text {rd }}$ ed. Longman Group United Kingdom. pp. 286-360.

Durr, G. and Lorenzl, G. (1980). Potato production and utilization in Kenya. International Potato Center, Nairobi.

Guar, P.C., Singh, B., Pandey, S.K., Marwaha R.S. and Kumar, D. (1999). A new high dry matter potato variety for chipping. Current Science 79:722-724.

Hamernik, A.J. and Hanneman, Jr.R.E. (1998). Breeding haploid species potato that chip from cold storage. American J. Potato Research 75 (6): 278-279.

International Federation of Fruit Juice Producers (1985). Determination of sugar (Luff-Schoorl method). No.4. pp.1-5.

Kabira, J.N. (2000). French fries and crisps processing characteristics of selected potato varieties in Kenya. African Potato Association Conference Proceedings vol.5: 507-511.

Kabira, J.N. (2002). Suitability of four promising clones for storage and processing into potato crisps and frozen chips (French fries). KARI Scientific Conference 11-15 Nov, KARI HQ, Nairobi.

Kabira, J.N and Lemaga, B. (2006). Potato Processing: Quality Evaluation procedures for research and food 
industries applications in East and Central Africa. Kenya Agricultural Research Institute, Nairobi, Kenya.

Kabira, J.N. (2007). Potato Policies and Standards in East and Central Africa. Kenya Agricultural Research Institute Institute, Nairobi, Kenya.pp 9-15.

Krokida, M.K., Maroulis, Z.B. and Saravacos, G.D. (2001). The effect of method of drying on the colour of dehydrated products. Int. J. Food Sci. \& Tech. 36: 5359.

Kulkarni, K.D and Govinden, N. 1994. Crisp Quality of Two Potato Varieties: Effects of Dehydration and Rehydration. J Sci. Food Agric. 64 (2): 205-210

Kumar, D., Singh B.P., Kumar, P. (2004). An overview of the factors affecting sugar content of potatoes. Central Potato Research Institute, Ann. Appl. Biol. (2004), 145:247-256.

Ludwig, J.W. (1972). Determination of the dry matter content of potatoes by weighing in water. Institute for Storage and Processing of Agricultural Produce (IBVL), Wageningen, Holland.

Larmond, E. (1977). Methods for sensory evaluation of food. Food Research Institute, Central Experiment Farm, Canada Dept. of Agriculture, Ottawa.

Lulai, E. and Orr, P.H. (1979). The influence of specific gravity on oil content of chips. Am. Potato J. 56,379390.

Lung'aho, C., Kabira, J.N. (1999). A guide to growing table potatoes. Kenya Agricultural Research Institute, Nairobi, Kenya.

Ministry of Agriculture (MoA). (2005). Potato Standards In: The Crop Production and Livestock Act. Kenya Gazette supplements no.38, Nairobi.
Ministry of Agriculture (MoA). (2007). Challenges in potato research. In: The National Policy on Potato Industry, Presentation during the potato stakeholders meeting at KARI head quarters, Nairobi, Kenya.

Olsson , K., Svensson, R. and Roslund, C. (2004). Tuber components affecting acrylamide formation and colour in fried potato: variation by variety, year, and storage temperature and storage time. J. Sci. Food and Agri. 84 (5): 447 - 458.

Potato Chips/Snack Food Association. (1987). Fry colour standards for potatoes for chipping. USA.

Rojo F. J and Vincent J. F. V. (2008). Fracture properties of potato crisps. Int. J. Food Sci. \& Techn. 43: 752760.

Smith, O. (1975). Potato chips. In: Potato processing, $3^{\text {rd }}$ Ed. Avi Publ.Co. Inc. Westport, Conn.

Salvador, A., Varela, P., Sanz, T. And Fiszman, S.M. (2009). Understanding potato crispy texture by simultaneous fracture and acoustic measurements, and sensory analysis. J. Food Sci. and Tech. 42 763767 .

Surkan, S., Albani O. and Ramallo L. (2009). Influence of storage conditions on sensory shelf-life of yerba mate. Journal of Food Quality 32: 58-72.

Walingo, A., Lung'aho, C., N'gang'a, N., Kinyae, P.M. and Kabira, J.N. (2004). Potato marketing, storage, processing and utilization in Kenya. Proceedings of $6^{\text {th }}$ Triennial congress of the African potato Association, Agadir, Morocco.

Walingo, A., Lung'aho, and Kabira, J.N. (2007). Characteristics of Potato varieties in the Kenyan processing agricultural sub-sector. Proceedings of the $13^{\text {th }}$ International Society for Tropical Root Crops Symposium, Morocco. pp. 408-416. 